BULLETIN OF THE

AMERICAN MATHEMATICAL SOCIETY

Volume 77, Number 4, July 1971

\title{
CORRECTION TO: AN ALGEBRA OF GENERALIZED FUNCTIONS ON AN OPEN INTERVAL; TWO-SIDED OPERATIONAL CALCULUS
}

BY GREGERS KRABBE

In my research announcement $A n$ algebra of generalized functions on an open interval; two-sided operational calculus, Bull. Amer. Math. Soc. 77 (1971), pp. 78-84, the last two lines immediately preceding 3.1 should read:

In fact, $1_{-}$(respectively, $1_{+}$) is a projector of $a \Omega$ onto the ideal $\left(1_{-} Q\right)$ (respectively, onto the ideal $\left.\left(1_{+} Q\right)\right)$, such that $\left(1_{-}\right)^{2}=1_{-}$, while $\left(1_{+}\right)^{2}=1_{+}$and $\left(1_{-}\right)\left(1_{+}\right)=0$. 